\title{
MuTAnT: a family of Mutator-like transposable elements targeting TA microsatellites in Medicago truncatula
}

\author{
Krzysztof Stawujak $^{1} \cdot$ Michał Startek $^{2} \cdot$ Anna Gambin $^{2,3} \cdot$ Dariusz Grzebelus $^{1}$
}

Received: 28 January 2015/Accepted: 10 May 2015/Published online: 17 May 2015

(c) The Author(s) 2015. This article is published with open access at Springerlink.com

\begin{abstract}
Transposable elements (TEs) are mobile DNA segments, abundant and dynamic in plant genomes. Because their mobility can be potentially deleterious to the host, a variety of mechanisms evolved limiting that negative impact, one of them being preference for a specific target insertion site. Here, we describe a family of Mutatorlike DNA transposons in Medicago truncatula targeting TA microsatellites. We identified 218 copies of MuTAnTs and an element carrying a complete ORF encoding a $m u$ $d r A$-like transposase. Most insertion sites are flanked by a variable number of TA tandem repeats, indicating that MuTAnTs are specifically targeting TA microsatellites. Other TE families flanked by TA repeats (e.g. TAFT elements in maize) were described previously, however we identified the first putative autonomous element sharing that characteristics with a related group of short non-autonomous transposons.
\end{abstract}

Keywords Barrel medic - DNA transposon - MULE . Simple sequence repeats

Electronic supplementary material The online version of this article (doi:10.1007/s10709-015-9842-5) contains supplementary material, which is available to authorized users.

Dariusz Grzebelus

dgrzebel@ogr.ar.krakow.pl; d.grzebelus@ogr.ur.krakow.pl

1 Institute of Plant Biology and Biotechnology, University of Agriculture in Krakow, Al. 29 Listopada 54, 31-425 Kraków, Poland

2 Institute of Informatics, University of Warsaw, Warsaw, Poland

3 Mossakowski Medical Research Centre, Polish Academy of Sciences, Warsaw, Poland

\section{Introduction}

Transposable elements (TEs) are mobile DNA segments present in most organisms. In higher plants, their content varies from $10 \%$ in Arabidopsis (Arabidopsis Genome Initiative 2000) to more than $80 \%$ in maize (Schnable et al. 2009). With respect to the transposition mechanism, TEs are divided into two classes; class I (retrotransposons) transpose via an RNA intermediate while class II (DNA transposons) change their location by a cut-and-paste mechanism characteristic for TEs carrying terminal inverted repeats (TIRs) or a rolling-circle mechanism typical for Helitrons (Wicker et al. 2007). A family of DNA transposons usually consists of one or a few autonomous elements capable of inducing their own transposition and more copies with internal deletions and rearrangements, referred to as non-autonomous, which lost the ability to transpose independently, however, they can be mobilized by a related autonomous element (Wessler 2006).

The canonical Mutator element was discovered in a maize stocks showing a high forward mutation rate (Robertson 1978). Since then, many Mutator-like elements (MULEs) have been identified in plants (Holligan et al. 2006), fungi (Chalvet et al. 2003), protozoans (Pritham et al. 2005; Lopes et al. 2009), and metazoans (Marquez and Pritham 2010). Autonomous $M u D R$-like elements carry two open reading frames, $m u d r A$ and $m u d r B$, the former coding for a transposase, while a function of the latter is not well defined. There is also a group of Mutatorlike autonomous elements, e.g. Jittery, carrying only $m u$ $d r A$-like ORF (Xu et al. 2004).

Tandemly repeated motifs of 2-6 nt are commonly referred to as microsatellites. Microsatellites exhibit variation in length, structure, frequency of individual motifs and genomic distribution (Schulman et al. 2005). In plants, (TA) 
repeats are more abundant compared to other dinucleotide motifs (Wang et al. 1994). Microsatellite regions are considered as hypervariable, as the number of tandem repeats can be changed following DNA polymerase slippage in the course of DNA replication. In plants, tandem repeats were shown to be preferentially associated with gene-rich regions (Morgante et al. 2002). In Medicago truncatula, microsatellites were found near genes, in $5^{\prime}$ and $3^{\prime}$ untranslated regions (UTRs) and introns (Mun et al. 2006).

Relationships between microsatellites and TEs were reported in insects (Meglécz et al. 2007), nematodes (Johnson et al. 2006), and plants (Temnykh et al. 2001; Tero et al. 2006). TEs targeting microsatellites were reported in Lepidoptera (Coates et al. 2010), rice (Akagi et al. 2001), and maize (Wang and Dooner 2006). Protomicrosatellites were shown to be created by Angela LTR retrotransposons in pea (Smýkal et al. 2009). Microsatellite-associated interspersed nuclear elements (MINEs) containing hitchhiking microsatellites, identified in moths (Coates et al. 2011) are another example of possible TEmicrosatellite relationships.

Here, we report on MuTAnTs, a novel family of MULEs present in M. truncatula and targeting (TA) microsatellite repeats. We identified 218 copies of MuTAnTs and characterized a putative autonomous element carrying a complete ORF encoding a $m u d r A$-like transposase.

\section{Materials and methods}

\section{Plant material}

Molecular analyses were performed on the reference line A17 'Jemalong', 2HA (an A17 derivative) and on 21 wild accessions of $M$. truncatula provided by INRA, Montpelier, France. Apart from M. truncatula, eight other Fabaceae species, i.e. Lupinus angustifolius L., L. luteus L., Pisum sativum L., Phaseolus vulgaris L., Trifolium pratense L., T. repens L., and Vicia faba L. were included in the analyses (Additional file 1). Each accession was represented by a single plant, seeds were germinated according to the Medicago Handbook (Garcia et al. 2006), plants were grown in pots in the greenhouse. Genomic DNA was isolated from the fresh tissue collected from ca. 8-weeksold plants with Plant DNeasy Mini Kit (Qiagen) following the manufacturer's protocol.

\section{Mining for MuTAnT copies in M. truncatula}

The family of non-autonomous elements flanked by TA repeats was identified following manual inspection of TE sequences reported by REPET (Flutre et al. 2011) for $M$. truncatula genome version 3.5.2 (Young et al. 2011) downloaded from medicago.org. Individual copies of MuTAnTs were mined with TARGET (Han et al. 2009) at www.iplantcollaborative.org using a MuTAnT sequence reported by REPET as a query. The related autonomous element was identified with TIRfinder (Gambin et al. 2013) using the following parameters: tirMask: GGGGTTTGCT AGAACA, tsdMask: N, tirSeqMismatches: 1, tsdSeqMismatches: 1, tirMaskMismatches: 3, tsdMaskMismatches: 0, and the aminoacid sequence of the maize mudrA transposase (Genebank acc. no. AAA21566) as a query with tblastn threshold of 1e-2. MuTAnT structure was analysed with mfold (Zuker 2003) and Dotlet (Junier and Pagni 2000). Sequence logos of TIRs were obtained with WebLogo (Crooks et al. 2004).

\section{MuTAnT diversity and evolutionary dynamics}

Sequences were processed with BioEdit (Hall 1999). Phylogenetic analyses including calculation of pairwise distances under Tajima-Nei model were performed with MEGA 5.2 (Tamura et al. 2011), frequencies were calculated with MS Excel. Possibility of past transposition events was demonstrated through the identification of sequences related to empty sites (RESites), which are paralogous sequences lacking TE insertion. Basic strategy included the comparison between the occupied locus and related empty sequence reveals the TSD events and gaps corresponding to the TE insertion (Le et al. 2000).

\section{PCR assay}

The PCR assay was used to investigate the distribution of AutoMuTAnT copies within Fabaceae, as well as to reveal the genomic distribution of MuTAnTs among M. truncatula ecotypes. Primers were designed using Primer3 (Koressaar and Remm 2007; Untergasser et al. 2012). PCR reactions were set up as followed: ca. $10 \mathrm{ng}$ of genomic DNA, $0.5 \mathrm{mM}$ dNTP, $0.4 \mu \mathrm{M}$ of forward primer, $0.4 \mu \mathrm{M}$ of reversed primer, $5 \%$ of DMSO, $1 \times$ buffer for AccuTaq LA DNA Polymerase, $0.2 \mathrm{U}$ of JumpStart AccuTaq LA DNA Polymerase Mix (Sigma Aldrich) in the total volume of $20 \mu \mathrm{l}$ (Additional file 1). The following PCR conditions were applied: $96{ }^{\circ} \mathrm{C} / 30 \mathrm{~s}, 30 \times\left(94{ }^{\circ} \mathrm{C} / 15 \mathrm{~s}, 62{ }^{\circ} \mathrm{C} / 30 \mathrm{~s}\right.$, $68{ }^{\circ} \mathrm{C} / 2 \mathrm{~min}$ ), and $68{ }^{\circ} \mathrm{C} / 30 \mathrm{~min}$. Amplified fragments were separated in $1.5 \%$ agarose gel in $1 \times$ TBE buffer and detected by ethidium bromide staining. Target bands were extracted from the gel with Wizard SV Gel and PCR Clean-Up System (Promega) as described by the manufacturer. Purified fragments were ligated into pGEMT vector and cloned into $E$. coli strain $D H 1 O B$ according to standard cloning procedure provided by Promega. Positive clones verified by PCR assay were Sanger-sequenced in Genomed SA, Warsaw, Poland. 


\section{Results}

\section{Identification and characterization of MuTAnTs}

Upon visual inspection of REPET output for M. truncatula, we identified a 292 bp-long element flanked by TA repeats. It comprised almost identical 144 bp-long TIRs spawning a foldback sequence, which showed a strong propensity to form a hairpin-like tertiary structure (Fig. 1). We identified 218 related elements ranging from ca. $200 \mathrm{bp}$ to over $1.6 \mathrm{~kb}$ and grouped them into a family named MuTAnT (Mutatorlike (TA) Targeting). A significant fraction (90\%) of these elements ranged in size from 200 to $300 \mathrm{bp}$, the mean TIR length was $47 \mathrm{bp}$ (Additional file 2). A related 4873 bp-long putative autonomous element, dubbed AutoMuTAnT (position 26,442,402-26,447,275 on chromosome 1), carried a single ORF composed of five exons, predicted to encode a 833 aa protein (Fig. 2) similar to Jittery transposase (e-value: 6e-79, GenBank acc. no. AAF66982, Xu et al. 2004). The insertion was flanked by long TA stretches comprising 59 and 27 perfect repeats on the $5^{\prime}$ and $3^{\prime}$ end, respectively. The sequence of AutoMuTAnT and majority rule consensus sequences of MuTAnT1 and MuTAnT2 subfamilies are provided in Additional file 3.

AutoMuTAnTs were present only within the Trifolieae tribe of the Fabaceae family, including white clover and all Medicago spp. but M. laciniata (Fig. 2a). Two wild ecotypes, $L 310$ and $L 530$, possibly carried other, likely truncated, copies of AutoMuTAnT, not present in the reference genome of A17 cv. 'Jemalong' (Fig. 2b).
Fig. 1 Structure of MuTAnT elements. a Self-alignment dotplot illustrating the structure of $M u T A n T$. Arrows on $X$ and $Y$ axes depict orientation of the four similar segments. b The foldback structure predicted with mfold (a)

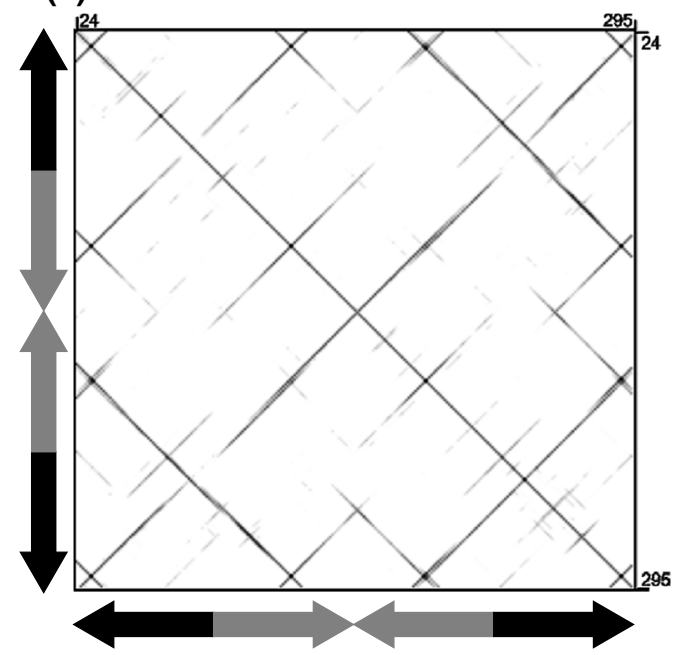

(b)

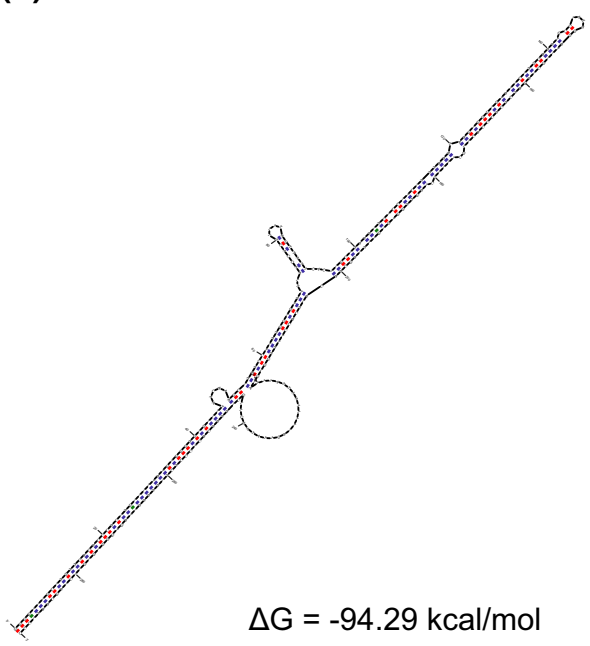

(a)

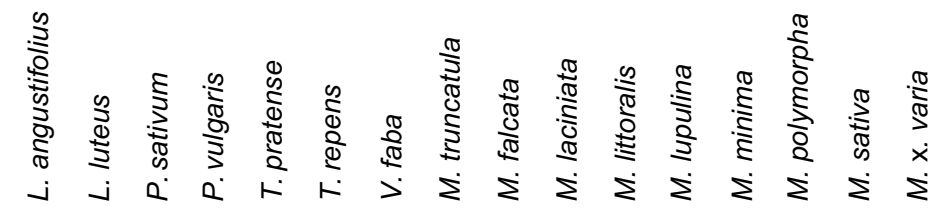

(b)

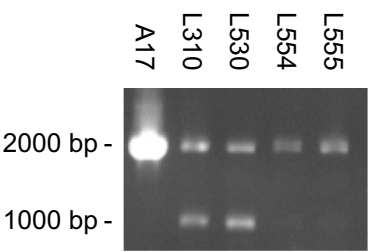

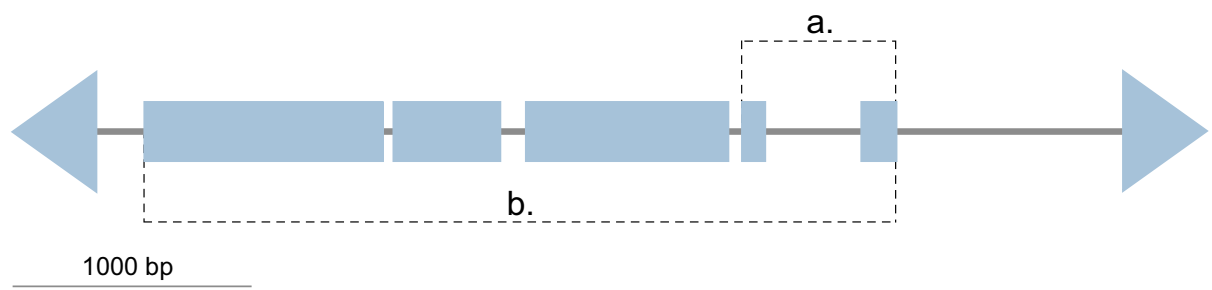

Fig. 2 PCR assay within DDE/DDD domain of the AutoMuTAnT transposase. Results of PCR assay with primers anchored in two regions of the DDE/DDD domain within selected Fabaceae species (a) and M. truncatula ecotypes (b) 


\section{Diversity of MuTAnTs}

Within the MuTAnT copies mined from the A17 genome assembly, twenty carried nested insertions or rearrangements. The remaining copies could be divided into two subfamilies, MuTAnT1 and MuTAnT2, grouping 74 and 124 elements, respectively (Fig. 3). The frequency of pairwise genetic distances calculated for all copies drawn as a histogram showed a bimodal distribution (Fig. 4). Fifty of the 198 elements were defective, completely or partially lacking one of TIRs (Additional file 4). Complete copies differed in terms of presence of the distal GGGG/CCCC stretches, as the number of $\mathrm{G}$ or $\mathrm{C}$ varied from zero to four.

In order to further analyze the distribution of MuTAnT insertions among $M$. truncatula accessions, we screened fourteen insertion sites using a PCR assay. In principle, length of the PCR product obtained with primers flanking the insertion site should indicate the presence or absence of a MITE copy. PCR amplification of regions comprising insertion sites was observed in 10 of 14 sites, all of them

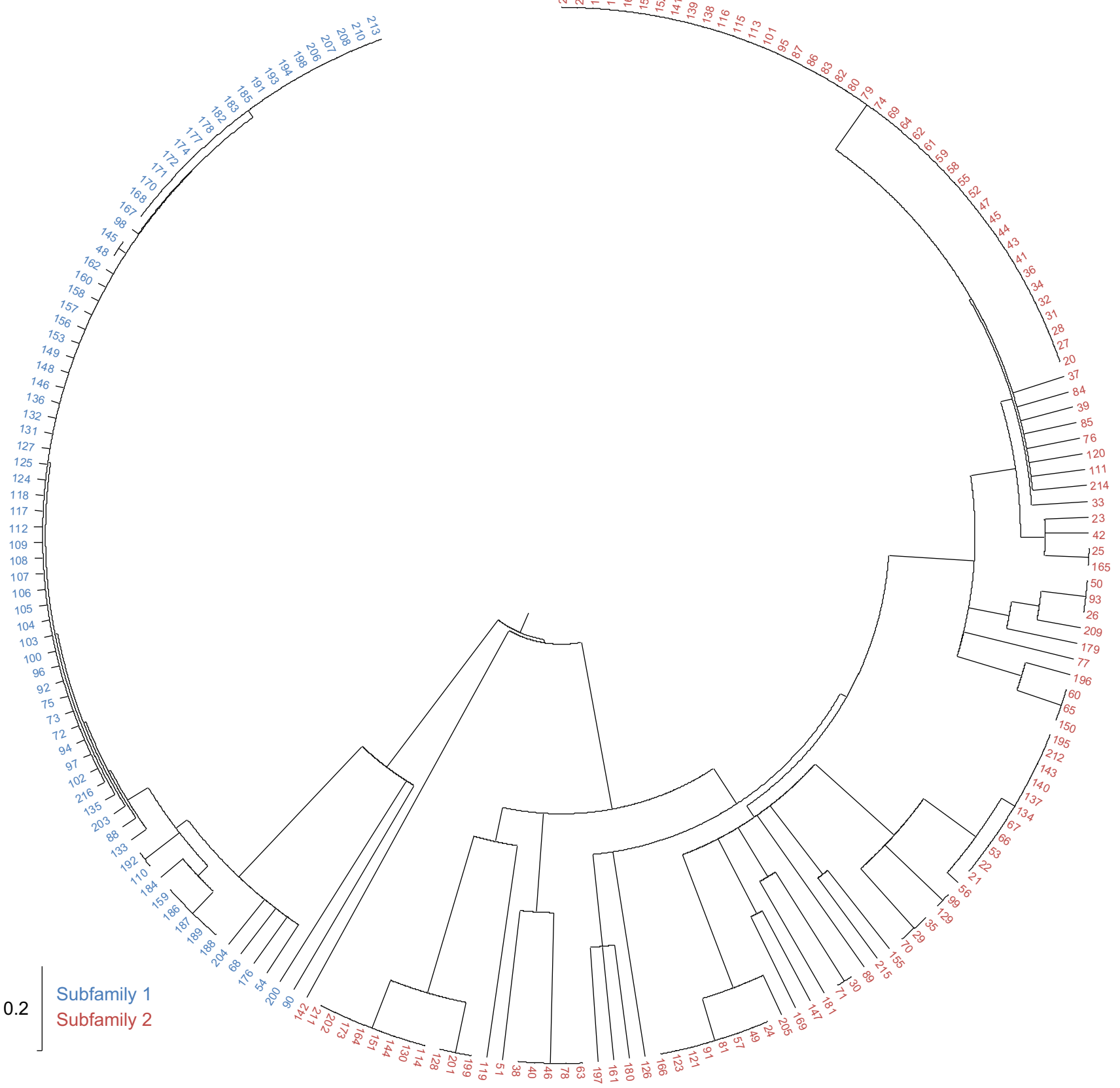

Fig. 3 Neighbor-joining tree representing diversity of 148 MuTAnTs 


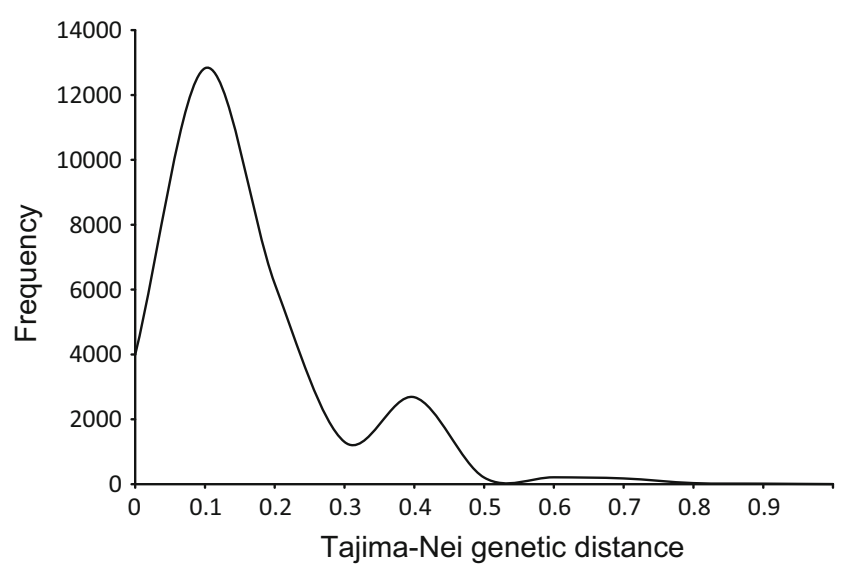

Fig. 4 Within family frequency of Tajima-Nei pairwise distances between MuTAnT copies

being polymorphic with respect to MuTAnT insertions (Fig. 5). In seven insertion sites, MuTAnT copies were present both in A17 and wild ecotypes, while in the remaining three sites, the insertions were unique for A17.

\section{Insertion site preference}

MuTAnTs were evenly distributed across chromosomes of $M$. truncatula with one insertion per $1.44 \mathrm{Mb}$ on average. A substantial fraction of insertions were present in generich regions, 36 of 218 identified copies occurred in introns or $5^{\prime}$ and $3^{\prime}$ UTRs, while additional 65 insertions were localized less than $1 \mathrm{~kb}$ away from genes. All $218 \mathrm{MuTAnT}$ insertions occurred in AT-rich regions, predominantly inside $(\mathrm{TA})_{\mathrm{n}}$ microsatellites varying in length and reaching up to 41 repeats. An average microsatellite flanking a MuTAnT insertion in the A17 reference genome consisted of $11.7( \pm 9.5 \mathrm{SD})$ TA repeats. Only 14 of the 218 copies were not inserted into perfect $(\mathrm{TA})_{\mathrm{n}}$ microsatellites. For these, the surrounding sequences indicated presence $9 \mathrm{nt}-$ long target site duplications (Fig. 6).

Additional insertion sites PCR-amplified from M. truncatula ecotypes carried on average 15 TA repeats on each
TE flank. In contrast, sequencing of a subset of corresponding empty insertion sites and RESite analysis indicated that empty target sites consisted of nine TA repeats on average (Table 1).

\section{Discussion}

We identified and characterized a novel family of MULEs named MuTAnT showing a strong preference for insertion into (TA $)_{n}$ microsatellites. We found MuTAnTs to be composed of long TIRs built up from modules forming a foldback structure, characteristic to previously reported families, such as Jittery in maize flanked by $181 \mathrm{bp}$-long TIRs (Xu et al. 2004) or FARE1 in Arabidopsis, a group of Foldback carrying long palindromic repeats on both ends (Windsor and Waddell 2000), currently classified as MULEs (Feschotte and Pritham 2007). The appurtenance of MuTAnTs to MULEs is further supported by similarity of the mudrA-like protein sequence of AutoMuTAnT and the Jittery transposase. The presence of AutoMuTAnT in white clover and in all but one analyzed Medicago species demonstrates that MuTAnTs are likely to predate the origin of the Medicago genus, as they were present in the most recent common ancestor of Trifolium and Medicago which lived at least 16 million years ago (Lavin et al. 2005).

To reveal the evolutionary history of the MuTAnT family, we calculated frequencies of pairwise distances between elements, as proposed previously for DINE-1 elements in Drosophila (Yang et al. 2006) and ATons in yellow fever mosquito (Yang et al. 2012). It indicated two bursts of transpositional activity giving rise to two subfamilies. We also analyzed the distribution of MuTAnT copies among wild ecotypes of $M$. tuncatula by a PCR assay. Insertion polymorphisms of ten sites and the unique presence of MuTAnT copies in three of those sites in A17 are indicative for recent transposition events similar to those reported previously for other plant species and TE families (Naito et al. 2006; Benjak et al. 2009; Grzebelus et al. 2009, 2011).

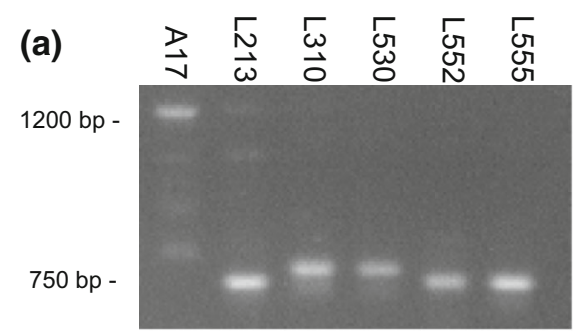

Fig. 5 PCR assay of the MuTAnT-32 insertion site. a Results of the PCR assay for five wild $M$. truncatula ecotypes and the reference line A17 with primers flanking the MuTAnT-32 insertion site. b Alignment of the corresponding empty and occupied variants at the MuTAnT-32 insertion site. The number of TA repeats is given in the subscript, the position of MuTAnT-32 is marked by three asterisks 
MuTAnT20 TTTACAAATTAGTAACATATTTATGTA***ATTTA-GTATTATAAGTATTTATTAATAT

MuTAnT24 CATAAGCCAATATTAACCAAATTTTATT ***AATTTTATTAGATCACTTTTAATTATTCA

MuTAnT30 TACTTACAAATATACAATTATTATATTA*** ATTATATTATAATCTCAGTTAATATATAT

Fig. 6 Target site duplication of four MuTAnT insertions. Target site duplications are in bold font, positions of MuTAnT insertions are marked by three asterisks

Table 1 Number of TA repeats surrounding MuTAnT insertion sites on $5^{\prime}$ and $3^{\prime}$ insertion flanks and corresponding empty sites in $M$. truncatula ecotypes and A17 cv. 'Jemalong'

\begin{tabular}{|c|c|c|c|c|}
\hline \multirow[t]{3}{*}{ Element } & \multirow[t]{3}{*}{ M. truncatula ecotypes } & \multicolumn{3}{|c|}{ Number of TA repeats } \\
\hline & & \multicolumn{2}{|c|}{ Occupied site } & \multirow[t]{2}{*}{ Empty sit } \\
\hline & & $5^{\prime}$ & $3^{\prime}$ & \\
\hline \multirow[t]{4}{*}{ MuTAnT-22 } & A17 & 25 & 6 & - \\
\hline & L310 & - & - & 9 \\
\hline & 530 & - & - & 7 \\
\hline & L555 & 8 & 111 & - \\
\hline \multirow[t]{3}{*}{ MuTAnT-25 } & A17 & 10 & 10 & - \\
\hline & L310 & - & - & 12 \\
\hline & L555 & - & - & 8 \\
\hline \multirow[t]{3}{*}{ MuTAnT-33 } & A17 & 21 & 9 & - \\
\hline & L310 & - & - & 9 \\
\hline & L530 & - & - & 4 \\
\hline \multirow[t]{2}{*}{ MuTAnT-42 } & A17 & 11 & 5 & - \\
\hline & L554 & 13 & 2 & - \\
\hline \multirow[t]{3}{*}{ MuTAnT-47 } & A17 & 11 & 12 & - \\
\hline & $\mathrm{L} 213$ & 8 & 12 & - \\
\hline & L555 & 9 & 12 & - \\
\hline \multirow[t]{4}{*}{ MuTAnT-52 } & A17 & 6 & 22 & - \\
\hline & L310 & 6 & 13 & - \\
\hline & L554 & 3 & 12 & - \\
\hline & L555 & 7 & 9 & - \\
\hline \multirow[t]{2}{*}{ MuTAnT-63 } & A17 & 24 & 22 & - \\
\hline & L555 & - & - & 11 \\
\hline
\end{tabular}

Precise determination of TSDs for most copies was impeded due to the repetitive nature of the flanking sequences. In addition, a high proportion of defective copies was revealed, as $25 \%$ of all identified MuTAnTs lacked a significant portion of one or both TIRs. Even if both TIRs were present, they varied in terms of deletions of one or more of the four distal nucleotides of TIRs (GGGG/ CCCC). Nevertheless, we showed that MuTAnTs generated 9 nt-long TSD, which in general is typical for MULEs.

$M u T A n T$ insertion sites are frequently located in proximity to genes, mostly less than $3 \mathrm{~kb}$ downstream or upstream from the adjacent coding region, with the number of insertions decreasing with the distance from genes. A similar tendency for insertion into gene-rich regions was reported early with the discovery of MITEs (Bureau and Wessler 1992, 1994) and was supported by subsequent studies (Yang et al. 2001; Sampath et al. 2013). As MuTAnTs are short, non-autonomous and relatively numerous in M. truncatula, they resemble MITEs both in terms of their structure and mode of operation. Notably, all MuTAnT insertions present within transcribed regions were located in UTRs or introns.

A hallmark of MuTAnTs activity is their propensity to insert into (TA) microsatellites. Affinity to insert into $(\mathrm{TA})_{\mathrm{n}}$ microsatellites provides a direct barrier against their insertions into coding regions. the apparent preference of MuTAnTs for insertion into TA repeats is possibly their survival strategy. Weak selection pressure imposed on microsatellite sites may favor TE families adapted to target microsatellites and use them as 'safe havens.' On the other hand, insertions proximal to coding regions can still introduce more subtle regulatory changes on the expression of adjacent genes. It is interesting to compare MuTAnTs to AhMITEs, a family of short MULEs inserting into AT-rich but non-microsatellite regions of the peanut genome (Shirasawa et al. 2012). Notably, we observed a similar behavior also in a minor group of MuTAnTs. Thus, it is possible that both families represent successive stages of the evolutionary process of exploiting microsatellites as target sites, with AhMITEs being a transitional form. TAFT and Micron elements identified in maize and rice, respectively, also show preference for insertion into (TA) $)_{n}$ microsatellites which suggests that the strategy may be more widespread, as it evolved independently in several unrelated families of DNA transposons.

Acknowledgments The research was financially supported by the Polish National Science Center, Project HARMONIA No. 2012/06/ M/ST6/00438 and by the Polish Ministry of Science and Higher Education fund for statutory activity of the University of Agriculture in Krakow.

Open Access This article is distributed under the terms of the Creative Commons Attribution 4.0 International License (http:// creativecommons.org/licenses/by/4.0/), which permits unrestricted use, distribution, and reproduction in any medium, provided you give appropriate credit to the original author(s) and the source, provide a link to the Creative Commons license, and indicate if changes were made. 


\section{References}

Akagi H, Yokozeki Y, Inagaki A, Mori K, Fujimura T (2001) Micron, a microsatellite-targeting transposable element in the rice genome. Mol Genet Genomics 266:471-480

Arabidopsis Genome Initiative (2000) Analysis of the genome sequence of the flowering plant Arabidopsis thaliana. Nature 408:796-815

Benjak A, Boué S, Forneck A, Casacuberta JM (2009) Recent amplification and impact of MITEs on the genome of grapevine. Genome Biol Evol 1:75-84

Bureau TE, Wessler SR (1992) Tourist: a large family of small inverted repeat elements frequently associated with maize genes. Plant Cell 4:1283-1294

Bureau TE, Wessler SR (1994) Stowaway: a new family of inverted repeat elements associated with the genes of both monocotyledonous and dicotyledonous plants. Plant Cell 6:907-916

Chalvet F, Grimaldi C, Kaper F, Langin T, Daboussi M-J (2003) Hop, an active Mutator-like element in the genome of the fungus Fusarium oxysporum. Mol Biol Evol 20:1362-1375

Coates BS, Sumerford DV, Hellmich RL, Lewis LC (2010) A helitron-like transposon superfamily from lepidoptera disrupts (GAAA)(n) microsatellites and is responsible for flanking sequence similarity within a microsatellite family. J Mol Evol 70:275-288

Coates BS, Kroemer JA, Sumerford DV, Hellmich RL (2011) A novel class of miniature inverted repeat transposable elements (MITEs) that contain hitchhiking $(\mathrm{GTCY})(\mathrm{n})$ microsatellites. Insect Mol Biol 20:15-27

Crooks GE, Hon G, Chandonia JM, Brenner SE (2004) WebLogo: a sequence logo generator. Genome Res 14:1188-1190

Feschotte C, Pritham EJ (2007) DNA transposons and the evolution of eukaryotic genomes. Annu Rev Genet 41:331-368

Flutre T, Duprat E, Feuillet C, Quesneville H (2011) Considering transposable element diversification in de novo annotation approaches. PLoS ONE 6:e16526

Gambin T, Startek M, Walczak K, Paszek J, Grzebelus D, Gambin A (2013) TIRfinder: a web tool for mining class II transposons carrying terminal inverted repeats. Evol Bioinform 9:17-27

Garcia J, Barker DG, Journet E-P (2006) Seed storage and germination. In: Mathesius U, Journet EP, Sumner LW (eds) Medicago truncatula handbook. Samuel Roberts Noble Foundation. http://www.noble.org/medicagohandbook/

Grzebelus D, Gładysz M, Macko-Podgórni A, Gambin T, Golis B, Rakoczy R, Gambin A (2009) Population dynamics of miniature inverted-repeat transposable elements (MITEs) in Medicago truncatula. Gene 448:214-220

Grzebelus D, Stawujak K, Mitoraj J, Szklarczyk M (2011) Dynamics of Vulmar/VulMITE group of transposable elements in Chenopodiaceae subfamily Betoideae. Genetica 139:1209-1216

Hall TA (1999) BioEdit: a user-friendly biological sequence alignment editor and analysis program for Windows 95/98/NT. Nucleic Acids Symp Ser 41:95-98

Han Y, Burnette JM, Wessler SR (2009) TARGeT: a web-based pipeline for retrieving and characterizing gene and transposable element families from genomic sequences. Nucleic Acids Res 37:e78

Holligan D, Zhang X, Jiang N, Pritham EJ, Wessler SR (2006) The transposable element landscape of the model legume Lotus japonicus. Genetics 174:2215-2228

Johnson PCD, Webster LMI, Adam A, Buckland R, Dawson DA, Keller LF (2006) Abundant variation in microsatellites of the parasitic nematode Trichostrongylus tenuis and linkage to a tandem repeat. Mol Biochem Parasitol 148:210-218
Junier T, Pagni M (2000) Dotlet: diagonal plots in a web browser. Bioinformatics 16:178-179

Koressaar T, Remm M (2007) Enhancements and modifications of primer design program Primer3. Bioinformatics 23:1289-1291

Lavin M, Herendeen PS, Wojciechowski MF (2005) Evolutionary rates analysis of Leguminosae implicates a rapid diversification of lineages during the tertiary. Syst Biol 54:575-594

Le QH, Wright S, Yu Z, Bureau T (2000) Transposon diversity in Arabidopsis thaliana. Proc Natl Acad Sci USA 97:7376-7381

Lopes FR, Silva JC, Benchimol M, Costa GGL, Pereira GAG, Carareto CMA (2009) The protist Trichomonas vaginalis harbors multiple lineages of transcriptionally active Mutator-like elements. BMC Genom 10:330

Marquez CP, Pritham EJ (2010) Phantom, a new subclass of Mutator DNA transposons found in insect viruses and widely distributed in animals. Genetics 185:1507-1517

Meglécz E, Anderson SJ, Bourguet D et al (2007) Microsatellite flanking region similarities among different loci within insect species. Insect Mol Biol 16:175-185

Morgante M, Hanafey M, Powell W (2002) Microsatellites are preferentially associated with nonrepetitive DNA in plant genomes. Nat Genet 30:194-200

Mun J-H, Kim D-J, Choi H-K et al (2006) Distribution of microsatellites in the genome of Medicago truncatula: a resource of genetic markers that integrate genetic and physical maps. Genetics 172:2541-2555

Naito K, Cho E, Yang G, Campbell MA, Yano K, Okumoto Y, Tanisaka T, Wessler SR (2006) Dramatic amplification of a rice transposable element during recent domestication. Proc Natl Acad Sci USA 103:17620-17625

Pritham EJ, Feschotte C, Wessler SR (2005) Unexpected diversity and differential success of DNA transposons in four species of Entamoeba protozoans. Mol Biol Evol 22:1751-1763

Robertson DS (1978) Characterization of a mutator system in maize. Mutat Res Mol Mech Mutagen 51:21-28

Sampath P, Lee S-C, Lee J, Izzah NK, Choi B-S, Jin M, Park B-S, Yang T-J (2013) Characterization of a new high copy Stowaway family MITE, BRAMI-1 in Brassica genome. BMC Plant Biol 13:56

Schnable PS, Ware D, Fulton RS et al (2009) The B73 maize genome: complexity, diversity, and dynamics. Science 326:1112-1115

Schulman AH, Gupta PK, Varshney RK (2005) Organization of retrotransposons and microsatellites in cereal genomes. In: Gupta PK, Varshney RK (eds) Cereal genomics. Springer, Netherlands, pp 83-118

Shirasawa K, Hirakawa H, Tabata S et al (2012) Characterization of active miniature inverted-repeat transposable elements in the peanut genome. Theor Appl Genet 124:1429-1438

Smýkal P, Kalendar R, Ford R, Macas J, Griga M (2009) Evolutionary conserved lineage of Angela-family retrotransposons as a genome-wide microsatellite repeat dispersal agent. Heredity 103:157-167

Tamura K, Peterson D, Peterson N, Stecher G, Nei M, Kumar S (2011) MEGA5: molecular evolutionary genetics analysis using maximum likelihood, evolutionary distance, and maximum parsimony methods. Mol Biol Evol 28:2731-2739

Temnykh S, DeClerck G, Lukashova A, Lipovich L, Cartinhour S, McCouch S (2001) Computational and experimental analysis of microsatellites in rice (Oryza sativa L.): frequency, length variation, transposon associations, and genetic marker potential. Genome Res 11:1441-1452

Tero N, Neumeier H, Gudavalli R, Schlötterer C (2006) Silene tatarica microsatellites are frequently located in repetitive DNA. J Evol Biol 19:1612-1619 
Untergasser A, Cutcutache I, Koressaar T, Ye J, Faircloth BC, Remm M, Rozen SG (2012) Primer3-new capabilities and interfaces. Nucleic Acids Res 40:e115

Wang Q, Dooner HK (2006) Remarkable variation in maize genome structure inferred from haplotype diversity at the $b z$ locus. Proc Natl Acad Sci USA 103:17644-17649

Wang Z, Weber JL, Zhong G, Tanksley SD (1994) Survey of plant short tandem DNA repeats. Theor Appl Genet 88:1-6

Wessler SR (2006) Eukaryotic transposable elements: teaching old genomes new tricks. In: Caporale LH (ed) The implicit genome. Oxford University Press, Oxford

Wicker T, Sabot F, Hua-Van A et al (2007) A unified classification system for eukaryotic transposable elements. Nat Rev Genet 8:973-982

Windsor AJ, Waddell CS (2000) FARE, a new family of foldback transposons in Arabidopsis. Genetics 156:1983-1995

Xu Z, Yan X, Maurais S, Fu H, O’Brien DG, Mottinger J, Dooner HK (2004) Jittery, a Mutator distant relative with a paradoxical mobile behavior: excision without reinsertion. Plant Cell 16:1105-1114

Yang G, Dong J, Chandrasekharan MB, Hall TC (2001) Kiddo, a new transposable element family closely associated with rice genes. Mol Genet Genomics 266:417-424

Yang H-P, Hung T-L, You T-L, Yang T-H (2006) Genomewide comparative analysis of the highly abundant transposable element DINE-1 suggests a recent transpositional burst in Drosophila yakuba. Genetics 173:189-196

Yang G, Wong A, Rooke R (2012) ATon, abundant novel nonautonomous mobile genetic elements in yellow fever mosquito (Aedes aegypti). BMC Genom 13:283

Young ND, Debellé F, Oldroyd GED et al (2011) The Medicago genome provides insight into the evolution of rhizobial symbioses. Nature 480:520-524

Zuker M (2003) Mfold web server for nucleic acid folding and hybridization prediction. Nucleic Acids Res 31:3406-3415 